\title{
PENGEMBANGAN MULTIMEDIA INTERAKTIF BERBASIS GUIDED DISCOVERY DENGAN AUTOPLAY PADA MATERI GARIS UNTUK SISWA SMP KELAS VII
}

\author{
Ivo Faujiah ${ }^{1}$ \\ ${ }^{1}$ Guru Matematika SMP Wahid Hasyim Malang \\ Email: Ipoh565@gmail.com
}

\begin{abstract}
Abstrak
Kegiatan pembelajaran di sekolah antara siswa dan guru merupakan salah satu contoh dari proses belajar. Dalam hal ini guru dapat dijadikan sebagai sumber belajar namun bukanlah satu-satunya. Salah satu yang dapat dijadikan media dalam pembelajaran adalah media pembelajaran dengan menggunakan multimedia yang bersifat interaktif yang berbasis guided discovery mengajak siswa untuk menjadi lebih mandiri dalam belajar dan dengan bantuan software AutoPlay dapat menjadikan multimedia interaktif semakin menarik.Pengembangan multimedia interaktif berbasis guided discovery dengan AutoPlay ini menggunakan model pengembangan ADDIE yang terdiri dari lima tahap yaitu: (1) Analysis (Analisis), (2) Design (Perancangan), (3) Development (Pengembangan), (4) Implementation (Pelaksanaan), dan (5) Evaluation (Evaluasi). Secara keseluruhan multimedia interaktif berbasis guided discovery dengan AutoPlay yang dikembangkan dinyatakan valid oleh ketiga validator yang terdiri dari validator ahli media dengan skor 3,64, ahli materi dengan skor 3,07, dan praktisi dengan skor 3,43, dan hasil rata-rata skor dari ketiga validator tersebut sebesar 3,24 dan telah memenuhi kriteria kevalidan yang ditetapkan. Sedangkan pada validasi user, multimedia interaktif berbasis guided discovery dengan AutoPlay dinyatakan valid dengan diperoleh rata-rata skor sebesar 3,45. Dengan demikian dapat disimpulkan bahwa multimedia interaktif berbasis guided discovery dengan AutoPlay dapat membantu siswa dalam memahami materi garis dan mendukung siswa belajar secara mandiri.
\end{abstract}

Kata-kata kunci: pengembangan, Interaktif, guided discovery, AutoPlay, materi garis

\section{PENDAHULUAN}

Pendidikan merupakan unsur penting dalam kehidupan, maka dari itu upaya untuk memajukan sistem pembelajaran harus terus dilakukan. Banyak upaya yang dilakukan dalam meningkatkan kualitas pembelajaran termasuk menggunakan teknologi sebagai salah satu media dalam membantu proses pembelajaran.

Pembelajaran matematika sendiri memiliki peran yang sangat penting untuk mendukung penguasaan dan pengembangan ilmu pengetahuan dan teknologi di era globalisasi saat ini. Matematika merupakan ilmu universal yang mendasari perkembangan teknologi modern, mempunyai peran penting dalam berbagai disiplin dan memajukan daya pikir manusia. Pembelajaran matematika diarahkan ke suatu tujuan agar siswa dapat memfungsikan matematika sebagai cara komunikasi, cara pikir, dan alat memecahkan masalah.

Persoalan sekarang adalah bagaimana menemukan cara yang terbaik untuk menyampaikan berbagai konsep yang diajarkan sehingga siswa dapat menggunakan dan mengingat lebih lama konsep tersebut. Bagaimana guru dapat berkomunikasi secara baik dengan siswa, dapat membuka wawasan berpikir yang beragam dari seluruh siswa, sehingga dapat mempelajari berbagai konsep dan cara mengkaitkan dalam kehidupan nyata. 
Tujuan yang ingin dicapai dalam pengembangan ini adalah menghasilkan media pembelajaran multimedia interaktif berbasis guided discovery dengan AutoPlay pada materi garis untuk siswa SMP kelas VII.

\section{Multimedia Interaktif}

Multimedia terdiri dari dua kata yaitu "multi" dan "media". Dalam Kamus Besar Bahasa Indonesia (Pusat Bahasa, 2005:761) multi adalah bentuk terikat yang berarti banyak, lebih dari satu, lebih dari dua atau berlipat ganda. Dan kata media merupakan bentuk jamak dari kata medium. Medium dapat didefinisikan sebagai perantara atau pengantar terjadinya komunikasi dari pengirim menuju penerima (Heinich dalam Daryanto, 2010:4). Menurut Criticos (dalam Daryanto, 2010:4) media merupakan salah satu komponen komunikasi, yaitu sebagai pembawa pesan dari komunikator menuju komunikan. Berdasarkan definisi tersebut, dapat dikatakan bahwa proses pembelajaran merupakan proses komunikasi. Daryanto (2010:4) juga mengemukakan tentang media bahwa media berasal dari bahasa Latin yang adalah bentuk jamak dari medium batasan mengenai pengertian media sangat luas, namun kita membatasi pada media pendidikan saja yakni media yang digunakan sebagai alat dan bahan kegiatan pembelajaran.

Daryanto (2010;5 1) mengemukakan bahwa multimedia interaktif adalah suatu multimedia yang dilengkapi dengan alat pengontrol yang dapat dioperasikan oleh pengguna, sehingga pengguna dapat memilih apa yang dikehendaki untuk proses selanjutnya. Contoh multimedia interaktif adalah aplikasi game, dan lain-lain.

\section{Model Pembelajaran Guided Discovery}

Dalam Bahasa Indonesia guided discovery berarti penemuan terbimbing. Yang dimaksudkan adalah penemuan yang dipandu oleh guru. Menurut Bruner (dalam Markaban, 2008:9), penemuan adalah suatu proses. Proses penemuan dapat menjadi kemampuan umum melalui latihan pemecahan masalah, praktek membentuk dan menguji hipotesis. Di dalam pandangan Bruner, belajar dengan penemuan adalah belajar untuk menemukan, dimana seorang siswa dihadapkan dengan suatlu masalah sehingga siswa dapat mencari jalan pemecahan. Model ini melibatkan suatu interaksi antara siswa dan guru dimana siswa mencari kesimpulan yang diinginkan melalui seluruh urutan pertanyaan yang diatur oleh guru untuk membantu siswa agar menemukan ide, konsep dan keterampilan yang sudah mereka pelajari.

Jadi, model pembelajaran guided discovery adalah model pembelajaran dimana guru membimbing siswa untuk menemukan kesimpulan dari urutan pertanyaan yang telah di atur oleh guru tersebut.

\section{Multimedia Interaktif berbasis Guided Discovery}

Multimedia interaktif berbasis Guided Discovery merupakan media pembelajaran matematika interaktif yang disusun berdasarkan langkah-langkah pada model pembelajaran Guided Discovery. Model ini melibatkan suatu interaksi antara siswa dan guru di mana siswa mencari kesimpulan yang diinginkan melalui seluruh urutan pertanyaan yang diatur oleh guru untuk membantu siswa agar menemukan ide, konsep dan keterampilan yang sudah mereka pelajari.

\section{AutoPlay}

Menurut Masruri (2011:5) AutoPlay merupakan sebuah software yang dapat digunakan untuk membuat suatu presentasi secara professional. Software ini didukung dengan tampilan yang sederhana tetapi mampu mengintegrasikan teks, gambar, video dengan baik.

\section{METODE}

Multimedia interaktif berbasis guided discovery dengan AutoPlay pada materi garis untuk siswa SMP kelas VII ini dikembangkan dengan model pengembangan ADDIE yang 
terdiri dari lima tahap yaitu: (1) Analysis (Analisis), (2) Design (Perancangan), (3) Development (Pengembangan), (4) Implementation (Pelaksanaan), dan (5) Evaluation (Evaluasi).

Jens data dari pengembangan ini terdiri dari dua macam yaitu data kuantitatif yaitu: (a) skor lembar validasi angket kebutuhan guru dan siswa; (b) skor lembar angket penilaian produk; (c) skor angket kebutuhan guru, kebutuhan siswa dan (d) skor angket validasi ahli desain, ahli praktisi, pengguna (user), serta kualitatif yaitu: (a) jawaban dari responden; (b) penarikan kesimpulan dari hasil analisis data yang berupa valid atau tidak valid; dan (c) komentar dan saran yang diperoleh dari penyebaran angket kebutuhan dan angket penilaian produk. Teknik analisis data disesuaikan dengan data yang ada. Data kuantitatif diperoleh dari penghitungan skor pada angket, sedangkan data kualitatif berupa kritik dan saran yang langsung ditulis oleh ahli media, ahli materi/isi, praktisi di lembar validasi kritik dan saran yang berupa evaluasi kebenaran media, bagian yang salah, dan saran perbaikan yang diisi oleh validator ahli, proktisi, dan user.

Lokasi yang digunakan dalam penelitian ini yaitu SMP Wahid Hasyim Malang yang melibatkan seorang guru matematika di sekolah tersebut dan 6 orang siswa.

Adapun prosedur pengembangan multimedia interaktif berbasis guided discovery dengan AutoPlay ini dapat dilihat pada Bagan 1 berikut. 


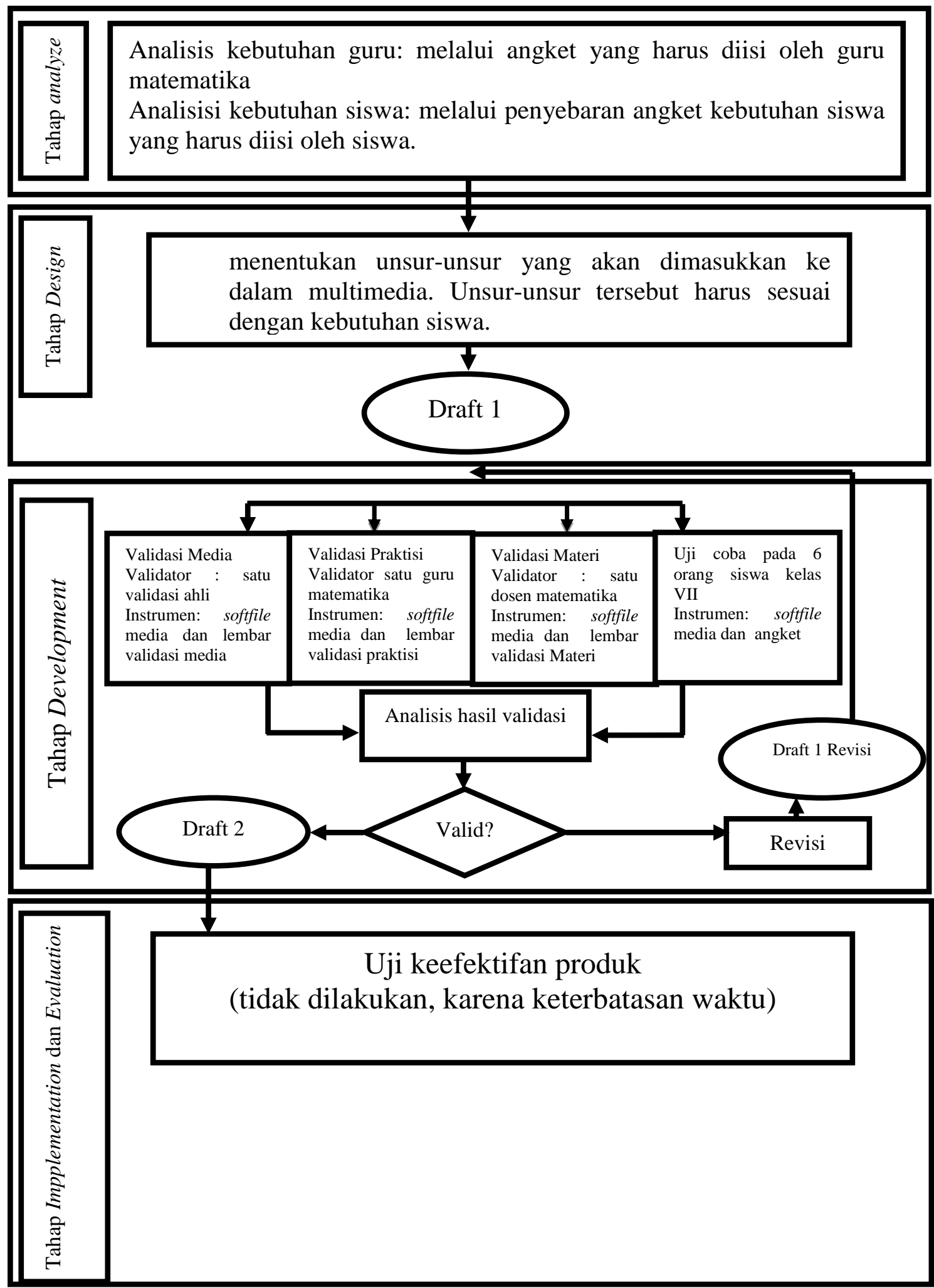

Bagan 1 Prosedut Pengembangan multimedia interaktif berbasis guided discovery dengan AutoPlay

\section{HASIL}

\section{Pengembangan Produk}

Hasil pengembangan ini berupa multimedia interaktif berbasis guided discovery dengan menggunakan software AutoPlay sebagai wadah yang menyatukan beberapa media 
menjadi satu pada materi garis untuk siswa SMP kelas VII. Materi pada multimedia interaktif ini disesuaikan dengan kurikulum 2013 SMP. Materi disusun dengan karakteristik model guided discovery.

Multimedia interaktif berbasis guided discovery dengan AutoPlay ini membahas materi garis tentang pengertian garis, bidang dan titik, hubungan antara garis, bidang, dan titik, kedudukan dua garis, dan membagi ruas garis menjadi beberapa bagian sama panjang. Tahap pertama yang dilakukan adalah tahan analyze meliputi analisis kebutuhan guru dan siswa, analisis teknologi, dan analisis kurikulum. Selanjutnya adalah tahap design, yaitu menyususn format multimedia interaktif dengan AutoPlay, mendesain, dan menyusun instrumen penilaian. Pada tahap development dilakukan validasi draf awal kepada validator, yaitu validator ahli, validator praktisi dan user. Sedangkan tahap implementation dan evaluation belum terlaksana karena keterbatasan waktu.

Multimedia interaktif berbasis guided discovery dengan AutoPlay secara umum terdiri dari beberapa bagian sebagai berikut.

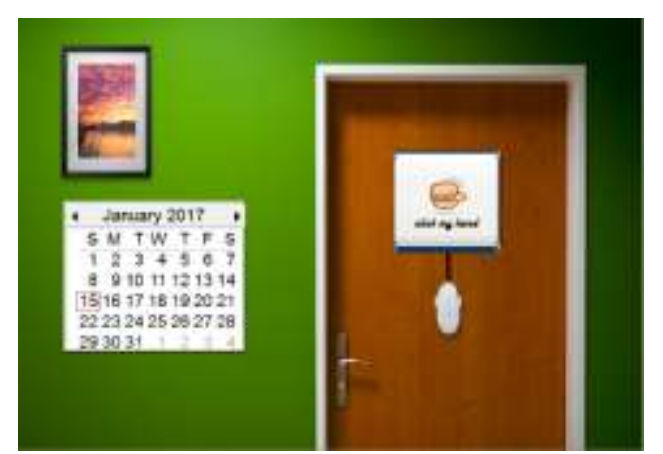

Gambar 1 Tampilan Halaman Pembuka

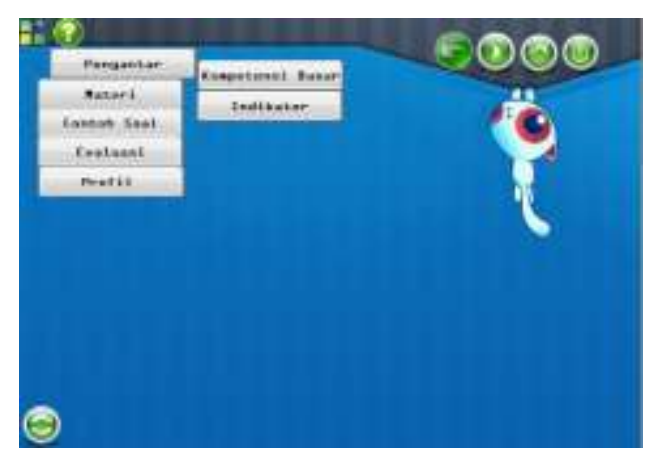

Gambar 3 Halaman Utama

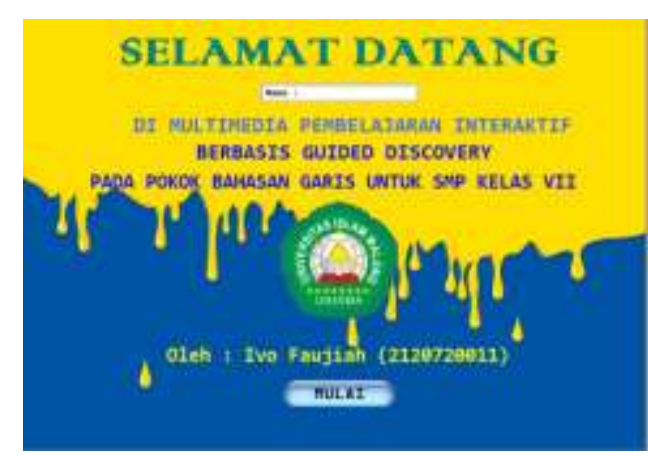

Gambar 2 Halaman Awal

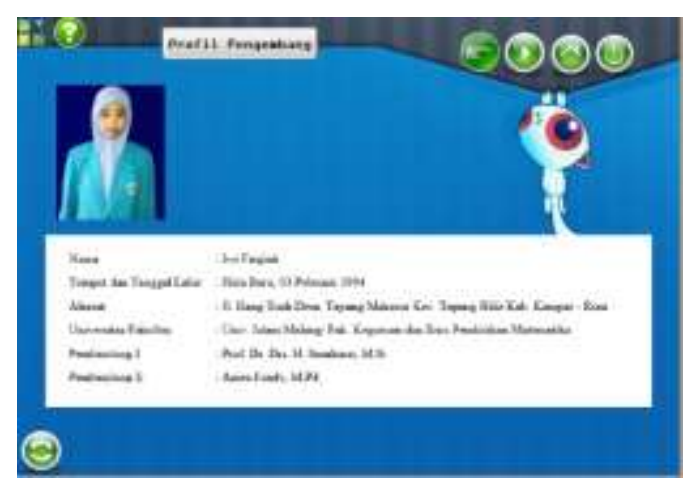

Gambar 4 Profil sebagai Penutup

\section{Telaah Ahli}

Pada uji validasi multimedia interaktif dengan AutoPlay, ada tiga validator yaitu validator ahli media, validator ahli materi/isi, dan praktisi. Berikut adalah hasil validasi ahli, praktisi, dan user.

Tabel 1: Hasil validasi Ahli Materi

\begin{tabular}{|c|c|c|c|c|c|c|}
\hline No & Aspek & & $n_{1}$ & $\sum X_{i}$ & $\mathbf{S}$ & Katagori \\
\hline 1. & Kelayakan isi & 33 & 8 & 4,125 & 4,125 & Valid \\
\hline 2. & Tampilan & 22 & 7 & 3.14 & 3.14 & Valid \\
\hline
\end{tabular}




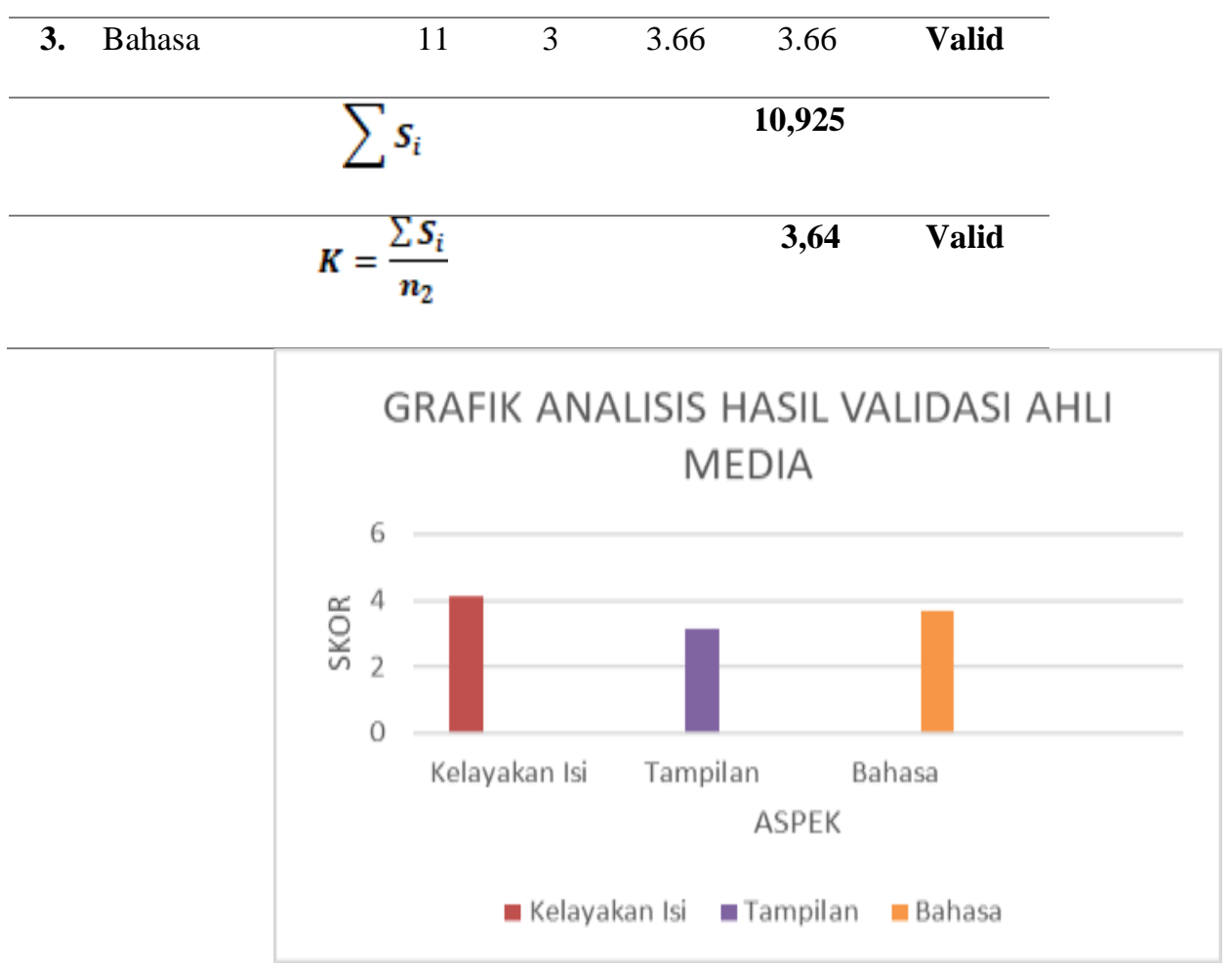

\section{Grafik 1 Hasil Validasi Ahli Media}

Tabel 2: Hasil Validasi Ahli Materi/Isi

\begin{tabular}{|c|c|c|c|c|c|c|}
\hline No. & Aspek & & $n_{1}$ & $\sum X_{i}$ & S & Katagori \\
\hline 1. & Isi dan Tujuan & 27 & 9 & 3,0 & 3,0 & Valid \\
\hline 2 & Teknis & 19 & 7 & 2,71 & 2,71 & $\begin{array}{c}\text { Kurang } \\
\text { Valid }\end{array}$ \\
\hline \multirow[t]{3}{*}{3} & Pembelajaran & 7 & 2 & 3,5 & 3,5 & Valid \\
\hline & & & & & 9,21 & \\
\hline & & & & & 3,07 & Valid \\
\hline
\end{tabular}




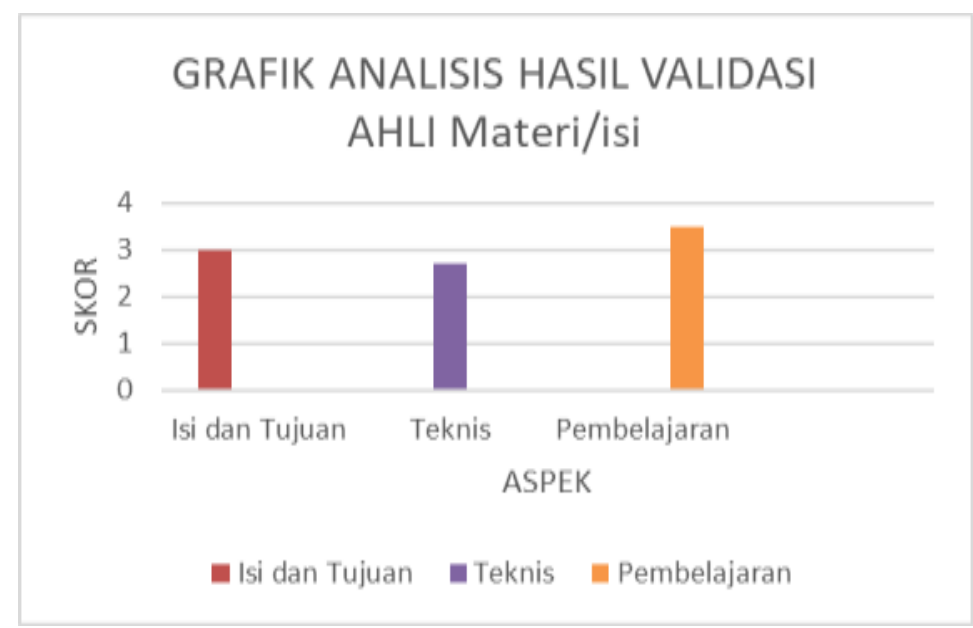

Grafik 2 Hasil Validasi Ahli Materi/Isi

Tabel 3: Hasil Validasi Praktisi

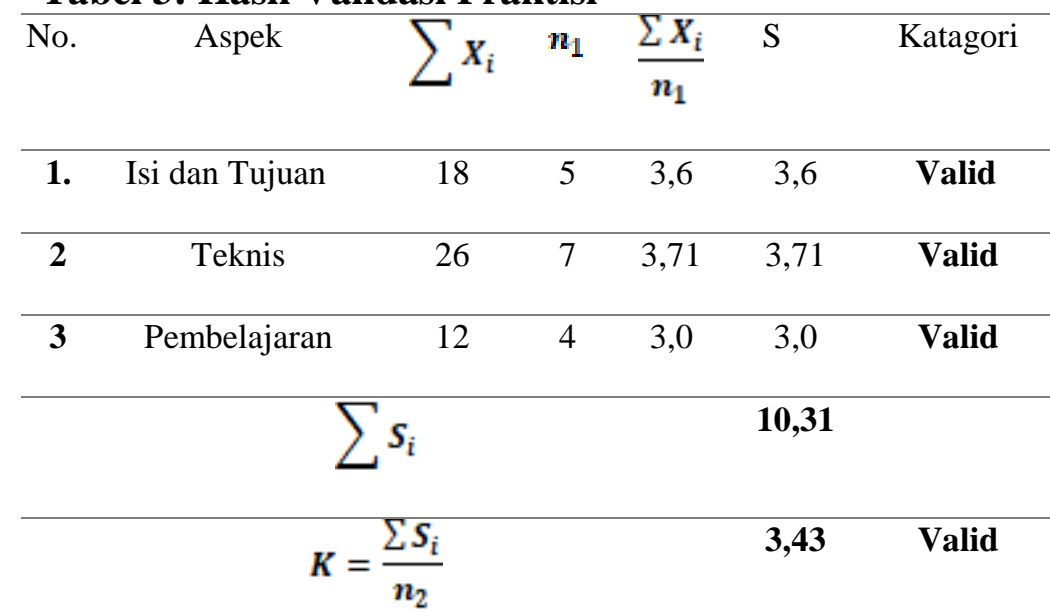

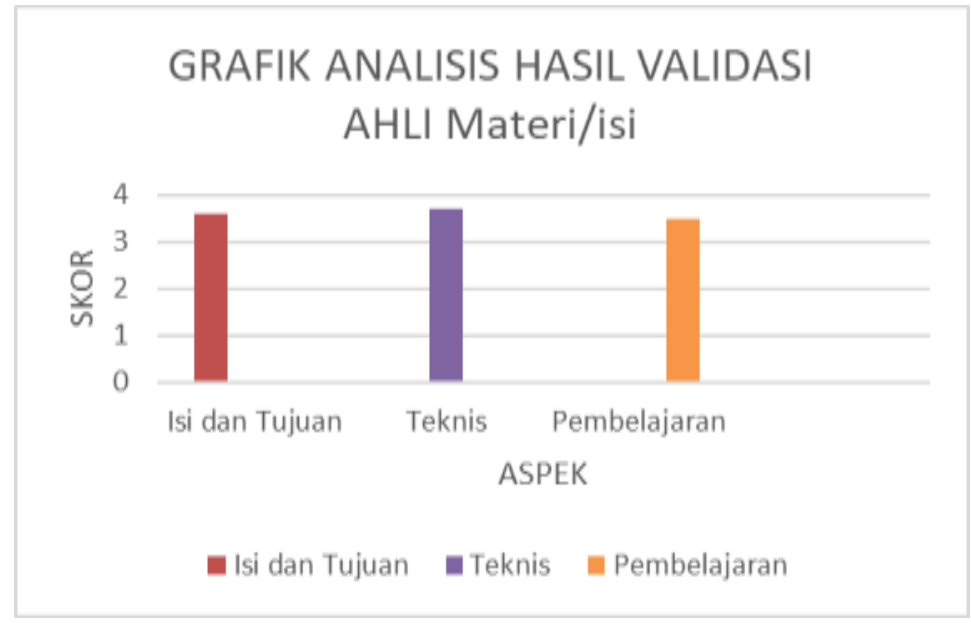

Grafik 3 Hasil Validasi Praktisi

Tabel 4: Hasil Analisis data Kelompok Ahli dan Praktisi 


\begin{tabular}{|c|c|c|c|}
\hline No. & Validator & $\mathrm{K}$ & Keterangan \\
\hline & Validator ahli media & 3,23 & Valid \\
\hline 2. & Validator ahli materi & 3,07 & Valid \\
\hline & Validator praktisi & 3,43 & Valid \\
\hline & 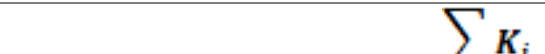 & 9,73 & \\
\hline & Rata-rata total $(\mathrm{NK})=\frac{\sum K_{i}}{N}$ & 3,24 & Valid \\
\hline
\end{tabular}

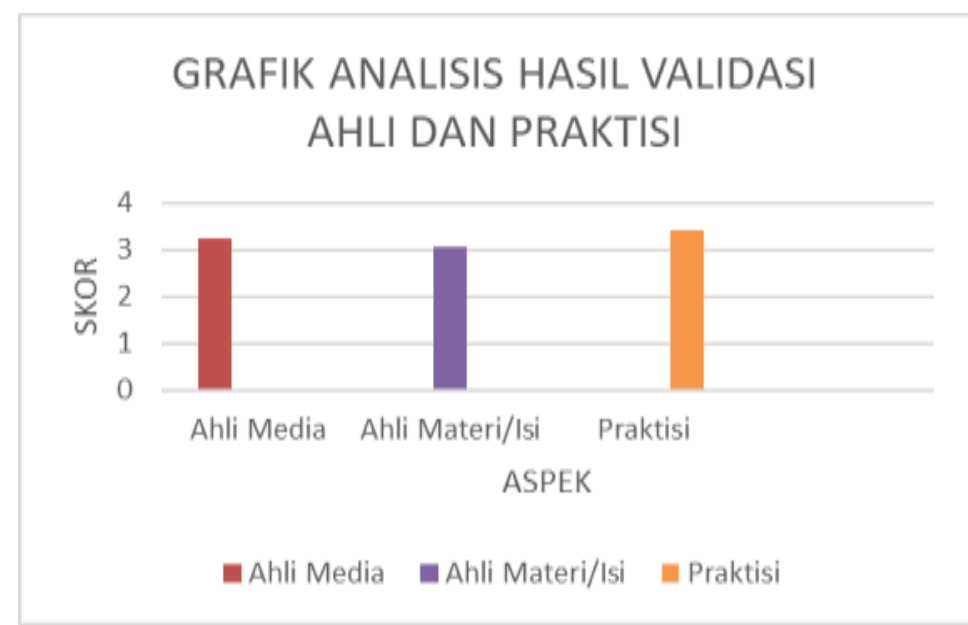

Grafik 4 Hasil Analisi Data Kelompok Ahli dan Praktisi

Dari Tabel 4 menunjukkan nilai rata-rata total dari semua validator adalah 3,24, maka dapat ditarik kesimpulan bahwa untuk multimedia interaktif berbasis guided discovery dengan AutoPlay materi garis untuk SMP kelas VII adalah valid.

Setelah multimedia interaktif dengan AutoPlay melalui uji validasi, selanjutnya duijucobakan kepada siswa dalam kelompok kecil, yaitu 6 siswa SMP Wahid Hasyim Malang kelas VII.

Tabel 5: Hasil Uji Coba user (Berkemampuan Matematika Baik)

\begin{tabular}{|c|c|c|c|c|c|c|}
\hline No. & Nama Siswa & $X_{\tilde{i}}$ & $n_{1}$ & $\frac{\sum X_{i}}{n_{1}}$ & $\mathbf{S}$ & Katagori \\
\hline 1. & User 5 & 53 & 15 & 3,53 & 3,53 & valid \\
\hline \multirow[t]{3}{*}{2.} & User 6 & 54 & 15 & 3,6 & 3,6 & valid \\
\hline & & & & & 7,13 & \\
\hline & & & & & 3,56 & valid \\
\hline
\end{tabular}

Tabel 6: Hasil Uji Coba user (Berkemampuan Matematika Sedang) 


\begin{tabular}{|c|c|c|c|c|c|c|}
\hline No. & Nama Siswa & $\sum \boldsymbol{X}_{i}$ & $n_{1}$ & $\frac{\sum X_{i}}{n_{1}}$ & $\mathbf{S}$ & Katagori \\
\hline 1. & User 3 & 52 & 15 & 3,46 & 3,46 & valid \\
\hline \multirow[t]{3}{*}{2.} & User 4 & 49 & 15 & 3,26 & 3,26 & valid \\
\hline & & & & & 6,72 & \\
\hline & $K=\frac{\Sigma}{r}$ & & & & 3,36 & valid \\
\hline
\end{tabular}

Tabel 7: Hasil Uji Coba user (Berkemampuan Matematika Kurang)

\begin{tabular}{|c|c|c|c|c|c|c|}
\hline No. & Nama Siswa & $\sum x_{i}$ & $n_{1}$ & $\frac{\sum X_{i}}{n_{1}}$ & $\mathbf{S}$ & Katagori \\
\hline 1. & User 1 & 52 & 15 & 3,46 & 3,46 & valid \\
\hline \multirow[t]{2}{*}{2.} & User 2 & 51 & 15 & 3,4 & 3,4 & valid \\
\hline & $\sum$ & & & & 6,86 & \\
\hline & $K=\frac{\sum}{n}$ & & & & 3,43 & valid \\
\hline
\end{tabular}

Tabel 8: Analisis Data Kelompok Validasi User

\begin{tabular}{|c|c|c|c|}
\hline No. & Kelompok Validasi User & $\mathbf{K}$ & Keterangan \\
\hline 1. & Uji pengguna siswa berkemampuan matematika baik & $\mathbf{3 , 5 6}$ & Valid \\
\hline 2. & $\begin{array}{l}\text { Uji pengguna siswa berkemampuan matematika } \\
\text { sedang }\end{array}$ & $\mathbf{3 , 3 6}$ & Valid \\
\hline 3. & $\begin{array}{l}\text { Uji pengguna siswa berkemampuan matematika } \\
\text { kurang }\end{array}$ & $3, \mathbf{4 3}$ & Valid \\
\hline & $\sum K_{\mathrm{i}}$ & 10,35 & \\
\hline & Rata-rata total $=\frac{\sum K_{i}}{W}$ & 3,45 & Valid \\
\hline
\end{tabular}

Dari Tabel 8 menunjukkan nilai rata-rata total dari semua kelompok user adalah 3,45, maka sesuai kriteria kevalidan dapat ditarik kesimpulan bahwa untuk multimedia interaktif berbasis guided discovery dengan AutoPlay dinyatakan valid.

Tanggapan Siswa

Dari hasil ujicoba didapatkan tanggapan kritik serta komentar dari siswa sebagai berikut. Tabel 9: Komentar dan Saran dari Siswa Subjek Komentar dan Saran 


\begin{tabular}{cl}
\hline User 1 & Memudahkan dalam pemahaman materi \\
\hline User 2 & $\begin{array}{l}\text { Menurut saya belajar dengan media ini membuat saya lebih } \\
\text { santai dan mudah paham }\end{array}$ \\
\hline User 3 & $\begin{array}{l}\text { Tidak membosankan belajar dengan mengunakan media } \\
\text { interaktif ini }\end{array}$ \\
\hline User 4 & Sangant menyenangkan, saya suka \\
\hline User 5 & Saya suka belajar seperti ini, lebih mudah memahami materi \\
\hline User 6 & $\begin{array}{l}\text { Sangat menyenangkan karena dapat belajar sekaligus } \\
\text { mendengarkan musik }\end{array}$ \\
\hline
\end{tabular}

\section{Revisi Produk}

Untuk mencapai produk yang mendekati sempurna dan memenuhi target ketepatan, kelayakan, dan kegunaan produk, maka multimedia interaktif berbasis guided discovery dengan AutoPlay matematika untuk materi garis ini melewati beberapa revisi sampai pada hasil akhir yang berupa media yang siap digunakan berupa: 1) Tampilan awal diberi kalender atau jam digital, 2) Tidak perlu backsong musik pada evaluasi, dan 3) Ukuran huruf diperjelas.

\section{PEMBAHASAN}

Dalam pengembangan ini pengembang mengembangkan media pembelajaran matematika multimedia interaktif berbasis guided discovery dengan AutoPlay pada materi garis untuk kelas VII SMP. Pengembangan media ini bersifat prosedural meliputi analisis, desain, pengembangan, penerapan dan evaluasi. Media ini dikemas dalam bentuk CD (Compact Disk) yang didesain dengan menggunakan AutoPlay Media Studio 8.

Hasil validasi dalam pengembangan multimedia interaktif berbasis guided discovery dengan AutoPlay yang telah dilakukan oleh ahli media, ahli materi, praktisi, dan pengguna (user) sudah valid untuk bisa digunakan sebagai media pembelajaran. Berdasarkan hasil analisis data, yang telah dijelaskan sebelumnya diperoleh nilai rata-rata skor validasi: 3,23 (valid) dari ahli media, 3,07 (valid) dari ahli materi, 3,43 (valid) dari ahli praktisi, dan 3,45 (valid) dari user. Dengan demikian media pembelajaran matematika multimedia interaktif berbasis guided discovery dengan AutoPlay pada materi garis untuk kelas VII SMP valid digunakan sebagai media pembelajaran pada pokok bahasan garis.

Terdapat kelebihan dan kelemahan pada pengembangan multimedia interaktif berbasis guided discovery dengan AutoPlay. Kelebihan dari media ini adalah: (1) materi yang disajikan dengan AutoPlay lebih menarik ; (2) kemenarikan tampilan pada multimedia interaktif berbasis guided discovery dengan AutoPlay dapat meningkatkan motivasi siswa dalam belajar; dan (3) media merupakan referensi media pembelajaran yang inovatif dan interaktif, karena kebanyakan guru masih jarang menggunakan media pembelajaran dalam sekolah sehingga siswa mudah jenuh selama pembelajaran berlangsung.

Selain itu, multimedia interaktif berbasis guided discovery dengan AutoPlay ini juga memiliki kelemahan. Adapun kelemahan dalam penggunaan media ini adalah media ini belum bisa digunakan pada teknologi berbasis android hanya bisa pada teknologi komputer saja dan belum dapat diperbesar ukuran layarnya (maximize).

\section{SIMPULAN DAN SARAN}

Produk dalam pengembangan ini adalah multimedia interaktif berbasis guided discovery dengan AutoPlay. Multimedia interaktif berbasis guided discovery dengan AutoPlay berdasarkan kurikulum 2013 yang membahas tentang garis. Adapun model pengembangan 
yang digunakan adalah ADDIE (Analyze, Design, Development, Implementation, dan Evaluation).

Dalam pemanfaatan multimedia interaktif berbasis guided discovery dengan AutoPlay diharapkan menjadi alat bantu pemahaman materi dan sarana belajar mandiri bagi siswa.

\section{DAFTAR RUJUKAN}

Anfa, Awim Iftiy. (2014). Pengembangan Media Pembelajaran Matematika Interaktif Berbasis Guided Discovery pada Materi Teorema Pythagoras untuk Siswa SMP Kelas VIII. Skripsi tidak diterbitkan. Malang: Program S1 Universitas Islam Malang.

Ariani, Niken dan Dany Haryanto. (2010). Pembelajaran Multimedia di Sekolah. Jakarta: Prestasi Pustaka.

Arsyad, Azhar. (2009). Media Pembelajaran. Jakarta: Rajawali Pers.

Daryanto. (2010). Media Pembelajaran. Yogyakarta: Satu Nusa.

Hamdani. (2011). Strategi BelajarMengajar. Bandung: Pustaka Setia.

Kadafi, Umar, dkk. (2013). Pengembangan Multimedia Pemblajaran Interaktif pada

Kompetensi Sistem Pernapasa Manusia Kelas VIII di SMPN 1 Gondang Tulungagung. (Online). (http://www.google.com/url?q=http://jurnal-

online.um.ac.id/data/artikel/artikelC93F8A9D5F1F07DFA07F0333AA901C71.pdf\&sa= U\&ved=0ahUKEwiRz7-

AjtzRAhVMrY8KHfZoAwsQFggGMAA\&usg=AFQjCNEKt87iNUgCamL-cSxX9v5eXxUEIA, diakses 12 januari 2016)

Kementerian Pendidikan dan Kebudayaan. (2014). Matematika untuk SMPMTs Kelas VII

Semester 2. Jakarta: Kementerian Pendidikan dan Kebudayaan.

Markaban. (2008). Model Penemuan Terbimbing pada Pembelajaran Matematika. SMK. Yogyakarta: PPPPTK.

Nihayah, Agustin. (2014). Pengembangan Multimedia Pembelajaran E-learning Berbasis Website pada Pokok Bahasan Lingkaran siswa Kelas VIII-A MTs. Al-Ma'arif Bocek kaangploso Tahun Pelajaran 2013/2014. Skripsi tidak diterbitkan. Malang: Program S1 Universitas Islam Malang.

Pusat Bahasa. (2005). Kamus Besar Bahasa Indonesia Edisi Ketiga. Jakarta: Balai Pustaka.

Santyasa, I Wayan. 2009. Metode Penelitian Pengembangan dan Teori. Makalah Disajikan dalam Pelatihan bagi para Guru TK, SD, SMP, SMA, dan SMK di Kecamatan Nusa Penida Kabupaten Klungkung, 12-14 Januari 2009.

Setyosari, Punaji. (2012). Metode Penelitian Pendidikan dan Pengembangan. Malang: Prenada Media Group.

Setyosari, Punaji. (2015). Metode Penelitian Pendidikan dan Pengembangan. Jakarta: Prenada Media Group.

Sudjana, Nana. (2011). Penilaian Hasil Proses Belajar Mengajar. Bandung: Remaja Rosdakarya.

Sugiyono. (2012). Metode Penelitian Pendidikan Pendekatan Kuantitatif, Kualitatif dan R \& $D$. Bandung: Alfabeta.

Sugiyono. (2013). Metode Penelitian Kuantitatif, Kualitatif dan $R \& D$. Bandung: Alfabeta. Sugiyono. (2014). Metode Penelitian Pendidikan; Pendekatan Kuantitatif, Kualitatif dan $R$ \& $D$. Bandung: Alfabeta.

Undang-undang Republik Indonesia Nomor 20 Tahun 2003 tentang Sistem Pendidikan Nasional. (2003). Jakarta: Departemen Pendidikan Nasional. 